\title{
Inulin-type fructans with prebiotic properties counteract GPR43 overexpression and PPAR $\gamma$-related adipogenesis in the white adipose tissue of high-fat diet-fed mice ${ }^{\text {is }}$
}

\author{
Evelyne M. Dewulf ${ }^{\mathrm{a}, 1}$, Patrice D. Cani ${ }^{\mathrm{a}, 1}$, Audrey M. Neyrinck ${ }^{\mathrm{a}}$, Sam Possemiers ${ }^{\mathrm{b}}$, Ann Van Holle ${ }^{\mathrm{b}}$ \\ Giulio G. Mucciolic, Louise Deldicque ${ }^{\mathrm{d}}$, Laure B. Bindels ${ }^{\mathrm{a}}$, Barbara D. Pachikian ${ }^{\mathrm{a}}$, Florence M. Sohet ${ }^{\mathrm{a}}$, \\ Eric Mignolet ${ }^{\mathrm{e}}$, Marc Francaux ${ }^{\mathrm{d}}$, Yvan Larondelle ${ }^{\mathrm{e}}$, Nathalie M. Delzenne ${ }^{\mathrm{a}, *}$ \\ ${ }^{a}$ Louvain Drug Research Institute, Metabolism and Nutrition Research Group, LDRI, Université Catholique de Louvain, 1200 Brussels, Belgium \\ ${ }^{\mathrm{b}}$ Laboratory of Microbial Ecology and Technology, Ghent University, 9000 Ghent, Belgium \\ ${ }^{\mathrm{c}}$ Bioanalysis and Pharmacology of Bioactive Lipids Laboratory, LDRI, Université catholique de Louvain, 1200 Brussels, Belgium \\ ${ }^{\mathrm{d}}$ Research Group in Muscle and Exercise Physiology, Université catholique de Louvain, 1348 Louvain-La-Neuve, Belgium \\ ${ }^{\mathrm{e}}$ Institut des Sciences de la Vie, Université catholique de Louvain, 1348 Louvain-la-Neuve, Belgium
}

Received 9 February 2010; received in revised form 4 May 2010; accepted 29 May 2010

\begin{abstract}
Inulin-type fructans (ITF) are nondigestible/fermentable carbohydrates which are able - through the modification of the gut microbiota - to counteract high-fat (HF) diet-induced obesity, endotoxemia and related-metabolic alterations. However, their influence on adipose tissue metabolism has been poorly studied until now. The aim of this study was to assess the influence of ITF supplementation on adipose tissue metabolism, by focusing on a $\mathrm{G}$ protein-coupled receptor (GPR), GPR43, as a potential link between gut fermentation processes and white adipose tissue development. Male C57bl6/J mice were fed a standard diet or an HF diet without or with ITF ( $0.2 \mathrm{~g}$ /day per mouse) during 4 weeks. The HF diet induced an accumulation of large adipocytes, promoted peroxisome proliferator activated receptor gamma (PPAR $\gamma$ )-activated differentiation factors and led to a huge increase in GPR43 expression in the subcutaneous adipose tissue. All those effects were blunted by ITF treatment, which modulated the gut microbiota in favor of bifidobacteria at the expense of Roseburia spp. and of Clostridium cluster XIVa. The dietary modulation of GPR43 expression seems independent of endotoxemia, in view of data obtained in vivo (acute and chronic lipopolysaccharides treatment). In conclusion, ITF, which promote gut fermentation, paradoxically counteract GPR43 overexpression induced in the adipose tissue by an HF diet, a phenomenon that correlates with a beneficial effect on adiposity and with potential decrease in PPAR $\gamma$-activated processes. (c) 2010 Elsevier Inc. All rights reserved.
\end{abstract}

Keywords: Gut microbiota; prebiotics; adipose tissue; high-fat feeding; GPR43; PPAR $\gamma$

\section{Introduction}

Obesity, which is characterized by an excess of fat mass, results from interactions between genetic and environmental factors. It is well known that a fat-enriched diet leads, especially in genetically predisposed individuals, to an accumulation of adipose tissue and to the development of metabolic alterations associated to weight gain. In addition, an innovative hypothesis has recently been proposed whereby another important aspect, the microbial ecology in humans, could be an important factor affecting energy homeostasis [1-4].

Over the past 5 years, the implication of the gut microbiota in energy homeostasis has been highlighted in several experimental

\footnotetext{
This project was supported a FNRS grant ( $\left.{ }^{\circ} 1.5 .095 .09 F\right)$.

* Corresponding author. Louvain Drug Research Institute, Nutrition and Metabolism Research Group, Université catholique de Louvain, PMNT Unit, Avenue Mounier 73/69, 1200 Brussels, Belgium. Tel.: +32 0276473 67; fax: +32027647359.

E-mail address: nathalie.delzenne@uclouvain.be (N.M. Delzenne).

${ }^{1}$ Equally contributed to this work.
}

studies. Indeed, Backhed et al. showed that germ-free mice resist to high-fat (HF) diet-induced obesity and that the conventionalization of adult germ-free mice produces a rapid increase in body fat content despite lower food intake [5,6]. Additionally, changes in gut microbiota composition were shown in different mice models of obesity, including ob/ob mice, and obese mice fed an HF-rich diet [7-10]. Several molecular targets were proposed which may link microbes-related events occurring in the colon with adipose tissue development, such as the so-called fasting-induced adipose factor. Conventionalization experiments showed that its intestinal expression is blunted after microbial colonization of the gut, thereby allowing increased lipoprotein-lipase (LPL) dependent fat storage in the adipose tissue [5]. Other molecular targets have been proposed recently, among which G protein-coupled receptors (GPR) 41 and 43 which are activated by short chain fatty acids (SCFA) generated by bacterial gut fermentation of nondigestible carbohydrates [11-13]. Among these two receptors, GPR43 - which is highly expressed in adipocytes - seems to be implicated in adipose tissue metabolism. Previous works showed that acetate and propionate inhibit isoproterenol-induced lipolysis in 3T3-L1 adipocytes [14] and also that the 
activation of GPR43 by acetate in vivo results in reduced plasma levels of free fatty acids, showing the inhibition of lipolysis [15]. These effects are mediated through GPR43 activation since they are abolished in GPR43-knockout animals [15]. In addition to the potential implication of GPR43 in lipolysis, its expression is induced in vitro in differentiating adipocytes. In fact, acetate and propionate stimulate adipogenesis via GPR43, since blocking GPR43 expression in 3T3-L1 cells, using siRNA, inhibits differentiation as well as fat accumulation in cells [14].

Given the important role of the gut microbial ecology in association with obesity, several studies have focused on the hypothesis that the onset of obesity may be influenced by targeted modification of the gut microbiota by specific nutrients. Indeed, the decrease in bifidobacteria occurring in obese mice fed an HF, sugarfree diet is counteracted through the administration of nondigestible oligosaccharides such as inulin-type fructans (ITF). Those compounds have been considered as prebiotics for year, namely, because they promote bifidobacteria development in the gut, with beneficial effects for host [16]. Indeed, we have already shown that, in several models of diet-induced or genetic obesity $[8,10,17]$, ITF supplementation counteracts white adipose tissue accumulation and other obesity related metabolic alterations such as endotoxemia, hepatic insulin resistance or gut barrier dysfunction. However, the adipose tissue metabolism in these conditions has been unexplored until now.

The aim of this study was to investigate the impact of gut microbiota modulation occurring upon ITF supplementation, on adipose tissue metabolism (lipid storage, adipogenesis and lipolysis) in a mouse model of diet-induced obesity, and to relate those effects with the changes in gut microbiota composition (prebiotic effect). We focused on the influence of ITF on GPR43 expression and related adipose tissue targets implicated in adipocyte differentiation: peroxisome proliferator activated receptor gamma (PPAR $\gamma$ ), CCAATenhancer-binding protein $\alpha(\mathrm{C} / \mathrm{EBP} \alpha)$ and adipocyte-specific genes such as the adipocyte P2 gene (aP2) [18].

\section{Methods and materials}

\subsection{Animals}

Ten-week-old male C57bl6/J mice (Charles River, Brussels, Belgium) were housed in groups of four mice per cage (eight per group) in a 12-h light/dark cycle (lights off at 6 p.m.) and were given free access to diet and water. The mice were separated into three groups: the control (CT) group was fed a CT diet (AO4, SAFE, Villemoison-surOrge, France), the HF group received an HF diet (Research Diets, New Brunswick, NJ, USA) and the HF-ITF group was fed the HF diet supplemented with $0.2 \mathrm{~g}$ /day per mouse of ITF prebiotics (oligofructose from Orafti, Oreye, Belgium) in water. Mice were treated during 4 weeks. The HF diet contained 60\% lipids (soybean oil and lard), 20\% protein, and $20 \%$ carbohydrates as energy content. Food intake, taking into account spillage, was recorded twice a week. Water consumption was also recorded twice a week to analyze prebiotic intake.

\subsection{Blood and tissue samples}

At the end of the experiment, 6-h-fasted mice were anaesthetized by intraperitoneal injection of $100 \mathrm{mg} / \mathrm{kg}$ of ketamine and $10 \mathrm{mg} / \mathrm{kg}$ of xylazine (Anesketin, Eurovet, Bladel, the Netherlands; Rompun, Bayer Belgium, Sint-Truiden, Belgium). Retro-orbital blood was collected with haematocrit capillaries in EDTA tubes, centrifuged ( $3 \mathrm{~min}, 13000 \times \mathrm{g}$ ), and plasma was stored at $-80^{\circ} \mathrm{C}$. The liver was removed, clamped in liquid $\mathrm{N}_{2}$ and kept at $-80^{\circ} \mathrm{C}$. Full and empty caecum and fat tissues (subcutaneous, visceral and epipidymal) were collected, weighed and frozen in liquid $\mathrm{N}_{2}$. Before freezing the subcutaneous adipose tissue, explants of $20 \mathrm{mg}$ were collected in order to evaluate the lipolytic activity (see below).

\subsection{Gut microbiota analysis}

For analysis of the microbial community composition, metagenomic DNA was extracted from the caecal content of all mice, using the QIAamp DNA stool mini kit (Qiagen, Venlo, Netherlands) according to the manufacturer's instructions. Denaturing Gradient Gel Electrophoresis (DGGE) on total bacteria, bifidobacteria, lactobacilli and the Bacteroides-Prevotella was performed to study the qualitative effect of the treatment on the structure and composition of the intestinal microbial community.
DGGE with a 45-60\% denaturant gradient were used to separate the polymerase chain reaction (PCR) products obtained with a nested approach for the 16S rRNA genes of bifidobacteria (primers BIF164f-BIF662r) and lactobacilli (SGLAB0158f-SGLAB0667) [19] and of the Bacteroides-Prevotella cluster (FD1, RbacPre)[20]. The first PCR round was followed by a second amplification with primers 338F-GC and 518R. The latter primers were also used to amplify the 16S rDNA of all bacteria on total extracted DNA. The DGGE patterns obtained were subsequently analysed using the Bionumerics software version 5.10 (Applied Maths, Sint-Martens-Latem, Belgium). In brief, the calculation of the similarities was based on the Pearson (product-moment) correlation coefficient. Clustering analysis was performed using the unweighted pair group method with arithmetic mean clustering algorithm to calculate the dendrograms of each DGGE gel and a combination of all gels. The latter was performed on a created composite dataset. The composite dataset of the 4 DGGE patterns was also used to perform principal coordinate analysis ( $\mathrm{PCOA}$ ). $\mathrm{PCoA}$ ordinations were calculated using the Pearson product-moment correlation coefficient. Within each character set, this coefficient subtracts each character from the average value and divides it by the variance of the character set.

Quantitative PCR ( $q P C R$ ) was performed to study the quantitative effect of the treatment on the composition of the intestinal microbial community. qPCR for total bacteria (using primers PRBA338f and P518r) and specific for bifidobacteria, lactobacilli or the Eubacterium rectal-Clostridium coccoides cluster were performed as reported by Possemiers et al. [21]. qPCR for Roseburia spp. was performed as described before [22], using the primers Ros-F1 and Ros-R1. qPCR for Firmicutes and Bacteroidetes was performed according to Guo et al. [23], using respectively the primers Firm934F-Firm1060R and Bact934F-Bact1060R. For the latter three protocols, the Power SYBR Green PCR Master kit (Applied Biosystems, Foster City) was used. The qPCR for Bacteroides-Prevotella spp. was performed as described by Rinttilä et al. [24], using the qPCR Core kit for SYBR Green I (Eurogentec, Seraing, Belgium) and primers Bacter140f and Bacter140r. All qPCR were performed with an ABI PRISM SDS 7000 Sequence Detection System (Applied Biosystems, Nieuwerkerk a/d Ijssel, the Netherlands). The statistical analysis was done on logarithmic values.

\subsection{Adipose tissue morphometry}

The mean adipocytes size was estimated on paraffin-embedded, hematoxylinstained, eosin-counterstained sections of subcutaneous tissue. The number of adipocytes per microscopic field (density) was determined at a magnification of $\times 100$. Total count ranged from 2900 to 5700 cells per condition. The mean surface area of the adipocytes $\left(\mu \mathrm{m}^{2}\right)$ was calculated using image analyzer software (Motic Image Plus 2.0 ML).

\subsection{Lipolytic activity}

Fresh explants (20 mg) of subcutaneous adipose tissue (SAT) were incubated with carbogen during $2 \mathrm{~h}$ at $37^{\circ} \mathrm{C}$ in a Krebs solution $\left[\mathrm{NaCl} 118 \mathrm{mM}, \mathrm{KCl} 4.8 \mathrm{mM}, \mathrm{KH}_{2} \mathrm{PO}_{4}\right.$ $1.2 \mathrm{mM}, \mathrm{MgSO}_{4} 1.2 \mathrm{mM}, \mathrm{CaCl}_{2} 1.25 \mathrm{mM}, \mathrm{NaHCO}_{3} 25 \mathrm{mM}$, glucose $5 \mathrm{mM}$ and $2.5 \%$ bovine serum albumin (BSA) free fatty acid] plus or minus insulin $10 \mathrm{nM}$ [25]. After incubation, tissues were frozen in liquid nitrogen and conserved at $-80^{\circ} \mathrm{C}$. The incubation medium was frozen at $-20^{\circ} \mathrm{C}$ until measurement of nonesterified fatty acids (NEFA) by enzymatic reactions and spectrophotometric detection of reaction end-products (Randox, United Kingdom). Lipolytic activity is expressed in nanomoles of NEFA released in the medium per $\mathrm{g}$ of adipose tissue after two hours of incubation with or without insulin [26]. The level of insulin-induced lipolysis inhibition corresponds to NEFA concentration in presence of insulin minus NEFA released in basal conditions.

2.6. Sodium dodecyl sulfate-polyacrylamide gel electrophoresis (SDS-PAGE) and immunoblotting

Frozen explants of SAT incubated for evaluating the lipolytic activity were homogenized in radioimmunoprecipitation assay (RIPA) buffer [ $25 \mathrm{mM}$ Tris- $\mathrm{HCl}, 150$ $\mathrm{mM} \mathrm{NaCl}, 0.1 \%$ SDS, $1 \%$ Tergitol type NP-40, 1\% sodium deoxycholate, a phosphatase inhibitor cocktail and a protease inhibitor cocktail]. The homogenates were then centrifuged for $20 \mathrm{~min}$ at $13,000 \times \mathrm{g}$ and the supernatant was removed. This step was repeated three times. Supernatants were combined with Laemmli sample buffer and separated by SDS-PAGE. After electrophoretic separation at $40 \mathrm{~mA}$, the proteins were transferred to a polyvinylidene fluoride (PVDF) membrane at $80 \mathrm{~V}$ for $2 \mathrm{~h}$, followed by western blot analysis. Membranes were then incubated in a $5 \%$ Blotto solution. Subsequently, membranes were incubated overnight at $4^{\circ} \mathrm{C}$ with an anti-phosphoAkt (Ser 473, Cell Signaling) diluted $(1: 1000)$ in Tris-buffered saline Tween-20 (TBST) containing 1\% BSA. Membranes were washed in TBST and incubated for 1 $\mathrm{h}$ at room temperature in a secondary antibody conjugated to horseradish peroxidase (1:10,000; Sigma, St. Louis, MO, USA). After additional washes, chemiluminescence detection was carried out using an Enhanced Chemiluminescent Western blotting kit (ECL Plus, Amersham Biosciences) and hyperfilms (Hyperfilm ECL, Amersham Biosciences). Then, the membranes were stripped and re-probed with an antibody recognizing the total form of Akt (Cell Signaling) to which all data were reported. The films were scanned with an ImageScanner using the Labscan software and quantified with the Image Master 1D Image Analysis Software (Amersham Biosciences). 


\subsection{Blood biochemical analysis}

Homeostasis Model Assessment (HOMA) was calculated as follows: [fasted glycemia $(\mathrm{mM}) *$ fasted insulinemia $(\mu \mathrm{U} / \mathrm{ml})] * 22.5$. Fasted glycemia was determined by enzymatic reactions and spectrophotometric detection of reaction end-products (Glucose PAP, Elitech Diagnostics). Plasma insulin concentration was determined in 5 ul of plasma using an ELISA kit (Mercodia, Upssala, Sweden), following the manufacturer's instructions.

\subsection{Real-time quantitative $P C R$}

Total RNA was isolated from subcutaneous adipose tissue using the TriPure isolation reagent kit (Roche Diagnostics Belgium, Vilvoorde). cDNA was prepared by reverse transcription of $1 \mathrm{mg}$ total RNA using the Kit Reverse transcription System (Promega, Leiden, The Netherlands). Real-time PCR were performed with the StepOne Plus real-time PCR system and software (Applied Biosystems, Den Ijssel, The Netherlands) using SYBR-Green (Applied Biosystems) for detection. Ribosomal protein L19 (RPL19) RNA was chosen as housekeeping gene. The targeted mouse genes are detailed in Table 1. All samples were run in duplicate in a single 96-well reaction plate and data were analyzed according to the $2^{-\Delta \mathrm{CT}}$ method. The identity and purity of the amplified product was checked through analysis of the melting curve carried out at the end of amplification.

\subsection{Fatty acid profile analysis in adipose tissue}

To determine the fatty acid profile in subcutaneous adipose tissue, $20 \mathrm{mg}$ of tissue were homogenized in $3 \mathrm{ml}$ of 2:1 chloroform:methanol. Homogenates were filtrated, and filters were rinsed with methanol and chloroform. Samples were centrifuged after addition of $\mathrm{KCl} 0.88 \%$, the upper phase was removed and $\mathrm{KCl} 0.88 \% \mathrm{MeOH}(1: 1)$ was added before a second centrifugation. The chloroform phase was evaporated under nitrogen flux. Fatty acids were methylated in a solution of $\mathrm{KOH}$ in methanol $(0.1 \mathrm{~mol} / \mathrm{L})$ at $70^{\circ} \mathrm{C}$ for $60 \mathrm{~min}$, then in a solution of $\mathrm{HCl}$ in methanol $(1.2 \mathrm{~mol} / \mathrm{L})$ at $70^{\circ} \mathrm{C}$ for $20 \mathrm{~min}$, and finally extracted with hexane. Fatty acid methyl esters (FAME) were quantified by a gas-liquid chromatograph (GC Trace ThermoQuest, Thermo-Finnigan, Milan, Italy) equipped with a flame ionization detector, automatic injector and a fused silica capillary column (100 m, $25.20 \mathrm{~mm}$ i.d.) coated with a film of biscyanopropyl polysiloxane (RT-2560; Restek, Interscience, Belgium) using $\mathrm{H}_{2}$ as the carrier gas operated at a constant pressure of $200 \mathrm{kPa}$. Injection was on column in order to inject the entire sample into the column head. The initial oven temperature was $80^{\circ} \mathrm{C}$, increased at $25^{\circ} \mathrm{C} / \mathrm{min}$ to $175^{\circ} \mathrm{C}$ (held for $25 \mathrm{~min}$ ), then increased at $10^{\circ} \mathrm{C} / \mathrm{min}$ to $205^{\circ} \mathrm{C}$ (held for $4 \mathrm{~min}$ ), then increased at $10^{\circ} \mathrm{C} / \mathrm{min}$ to $225^{\circ} \mathrm{C}$ (held for $20 \mathrm{~min}$ ) and finally decreased at $20^{\circ} \mathrm{C} / \mathrm{min}$ to $80^{\circ} \mathrm{C}$. The temperature of the flame ionisation detector was maintained at $255^{\circ} \mathrm{C}$. Hydrogen flow to the detector was $35 \mathrm{ml} / \mathrm{min}$, and airflow was $350 \mathrm{ml} / \mathrm{min}$. Each peak was identified and quantified by comparison of retention times with pure FAME standards (Alltech Associates, Deerfield, IL, USA; except CLA isomers from Nu-Chek Prep, Elysian, MN, USA). Each FA was expressed as a percentage of FAME reported (identified).

\subsection{Adipose tissue explants culture}

Subcutaneous adipose depots of 20 ten-week-old male C57bl6/J mice were precisely dissected; all visible vessels, particles, and conjunctive tissue were removed. Fat tissue was cut with scissors into small pieces $\left(4 \mathrm{~mm}^{3}\right)$ pooled and placed in Krebs buffer, $\mathrm{pH} 7.4$, containing $2 \%(\mathrm{w} / \mathrm{v})$ free fatty acid-BSA and penicillin $(100 \mathrm{IU} / \mathrm{ml})$, streptomycin $(100 \mu \mathrm{g} / \mathrm{ml})$, amphotericin B $(2.5 \mu \mathrm{l} / \mathrm{ml}$ ) (Invitrogen); $250 \mathrm{mg}$ of adipose tissue were rinsed in phosphate-buffered saline and incubated in $100-\mathrm{mm}$ petri dishes containing $10 \mathrm{ml}$ MEM with Earle's salts (Invitrogen) supplemented with $0.5 \%$ free fatty acid-BSA, penicillin $(100 \mathrm{IU} / \mathrm{ml})$, streptomycin $(100 \mu \mathrm{g} / \mathrm{ml})$, amphotericin B $(2.5$ $\mu \mathrm{l} / \mathrm{ml}$ ) (Invitrogen) and then cultured. All conditions were carried out in three different dishes $(n=3)$. The dishes were cultured for $24 \mathrm{~h}$ at $37^{\circ} \mathrm{C}$ in a $5 \% \mathrm{CO}_{2}$ atmosphere. The basal concentration of glucose in fresh medium was $5 \mathrm{mmol} / \mathrm{L}$ and those of cortisol and insulin were extremely low $(\approx 0.5 \mathrm{nmol} / \mathrm{L}$ and $3 \mathrm{pmol} / \mathrm{L}$, respectively $)$. Different pharmacological agents were used in various combinations in accordance with the experimental protocols. Troglitazone (10 $\mu \mathrm{M})$ (Sigma) and GW9662 (10 $\mu \mathrm{M})$ (Sigma) were diluted in DMSO which served as CT condition. Cell viability did not change over the course of culture (not shown). At the end of the experiment, the adipose material was rinsed in phosphate-buffered saline, collected, immediately frozen in liquid nitrogen, and stored at $-80^{\circ} \mathrm{C}$ until subsequent mRNA analysis.

\subsection{Chronic load with lipopolysaccharides (LPS)}

Ten-week-old male C57bl6/J mice (Charles River, Brussels, Belgium) were housed in a controlled environment in a 12-h light/dark cycle (lights off at 6:00 pm) and were given free access to diet and water. Mice were implanted subcutaneously with an osmotic minipump (Alzet Model 2004; Alza, Palo Alto, CA, USA) as previously described [27]. The pumps were filled either with Tween $0.1 \%$ /saline or LPS (from Escherichia coli 055:B5; Sigma) to infuse $300 \mu \mathrm{g} / \mathrm{kg} / \mathrm{day}$ for 4 weeks. At the end of the experiment, 6-h-fasted mice were anaesthetized as described supra. Fat tissues (subcutaneous, visceral and epipidymal) were collected, weighed and frozen in liquid $\mathrm{N}_{2}$

\subsection{Acute load with LPS}

Ten-week-old male C57bl6/J mice (Charles River, Brussels, Belgium) were housed in groups of three mice per cage (six per group) in a 12-h light/dark cycle (lights off at $6: 00 \mathrm{pm}$ ) and were given free access to diet (AO4, SAFE, Villemoison-sur-Orge, France) and water for acclimatizing. After $2 \mathrm{~h}$ of fasting, mice were intraperitoneally injected either with saline solution (CT group) or with LPS ( $5 \mathrm{mg} / \mathrm{kg}$, from Escherichia coli 055: B5; Sigma) (LPS group). Four hours after injection, mice were anaesthetized as described supra. Vena cava blood was collected in EDTA tubes, centrifuged ( 3 min, $13000 \times \mathrm{g}$ ) and plasma was stored at $-80^{\circ} \mathrm{C}$. Fat tissues (subcutaneous and epipidymal) were collected, weighed and frozen in liquid $\mathrm{N}_{2}$.

All mice experiments were approved by the local committee and the housing conditions were as specified by the Belgian Law of November 14, 1993 on the protection of laboratory animals (agreement no. LA 1230314) in accordance with the declaration of Helsinki.

\subsection{Statistical analysis}

Results are presented as mean \pm S.E.M. Statistical significance of difference between groups was assessed either by one-way analysis of variance (ANOVA) followed by post hoc Tukey's multiple comparison tests when comparing three groups or more, or by a Student's $t$ test when comparing 2 groups (Graph-Pad Prism Software, San Diego, CA, USA; www.graphpad.com). Data with different superscript letters are significantly different $(P<.05)$ according to the post hoc ANOVA statistical analysis. $*$ Significantly different from the CT group $(P<.05$, Student's $t$ test).

\section{Results}

\subsection{ITF promote selective changes in caecal microbial composition}

The weight of the caecal content is considered as a measure for the extent of bacterial fermentation and changes in this weight are therefore related with changes in the microbial activity or composition in the caecum. As compared to the CT diet, administration of the HF diet induced a significant decrease in the caecal content, an effect which was however counteracted by the co-administration of prebiotics with the HF diet (CT: $0.268 \pm 0.018^{\mathrm{a}}$; HF: $0.114 \pm 0.015^{\mathrm{b}}$; HF-ITF: $0.246 \pm 0.025^{\mathrm{a}} \mathrm{g}$ ). Changes were also observed in the bacterial counts as quantified by qPCR (Fig. 1A). Administration of the HF diet induced a decrease in total bacterial counts and in the counts of most

Table 1

Sequences for the primers used in real-time quantitative PCR

\begin{tabular}{|c|c|c|c|}
\hline & GenBank accession no. & Forward primer $\left(5^{\prime}\right.$ to $\left.3^{\prime}\right)$ & Reverse primer ( $5^{\prime}$ to $\left.3^{\prime}\right)$ \\
\hline RPL19 & NM_009078.1 & GAAGGTCAAAGGGAATGTGTTCA & CCTTGTCTGCCTTCAGCTTGT \\
\hline GPR43 & NM_146187.3 & TTCTTACTGGGCTCCCTGCC & TACCAGCGGAAGTTGGATGC \\
\hline $\operatorname{PPAR} \gamma$ & NM_011146.2 & CTGCTCAAGTATGGTGTCCATGA & TGAGATGAGGACTCCATCTTTATTCA \\
\hline $\mathrm{aP2}$ & NM_024406.1 & GATGCCTTTGTGGGAACCTG & GCCATGCCTGCCACTTTC \\
\hline $\mathrm{C} / \mathrm{EBP} \alpha$ & NM_007678.3 & GAGCCGAGATAAAGCCAAACA & GCGCAGGCGGTCATTG \\
\hline LPL & NM_008509.2 & TCTGTACGGCACAGTGG & CCTCTCGATGACGAAGC \\
\hline CD36 & NM_007643.3 & GCCAAGCTATTGCGACATGA & ATCTCAATGTCCGAGACTTTTCAAC \\
\hline TLR-4 & NM_021297.2 & GCAGAAAATGCCAGGATGATG & AACTACCTCTATGCAGGGATTCAAG \\
\hline $\mathrm{F} 4 / 80$ & NM_010130.2 & TGACAACCAGACGGCTTGTG & CAGGCGAGGAAAAGATAGTGT \\
\hline
\end{tabular}

CD36, cluster of differentiation 36; TLR-4, toll like receptor 4. 

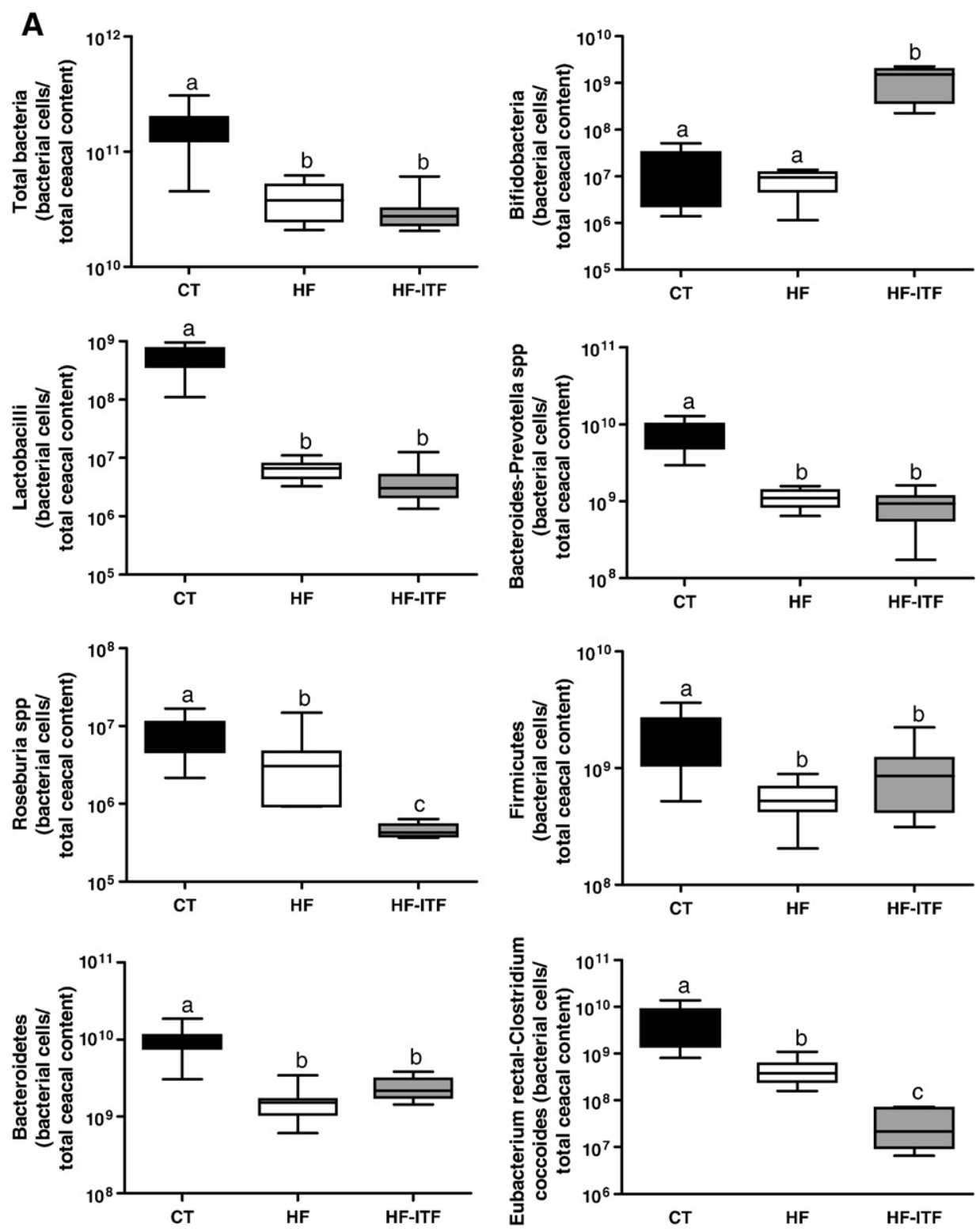

B

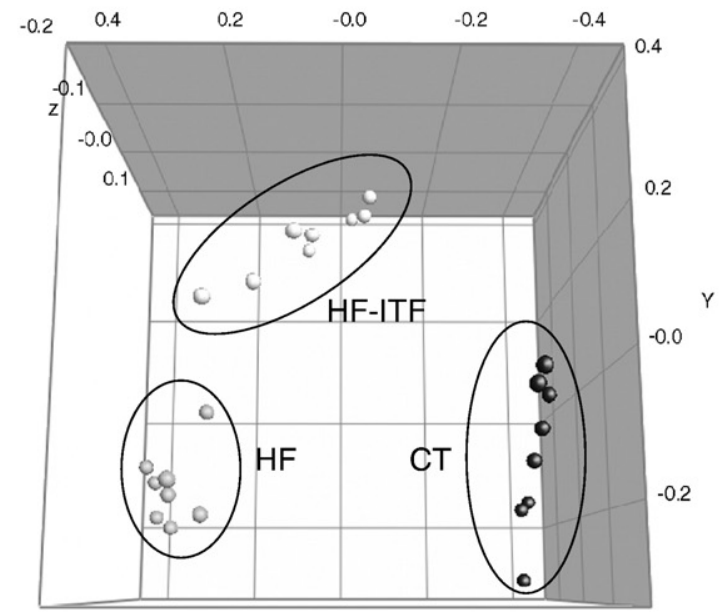

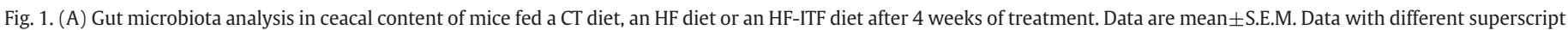

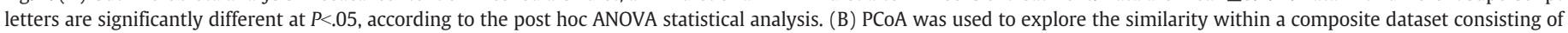

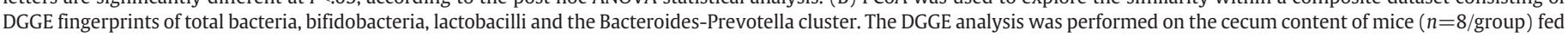
a CT diet (black symbols), an HF diet (grey symbols) or an HF-ITF diet (white symbols) during 4 weeks. 
$\hat{t}$
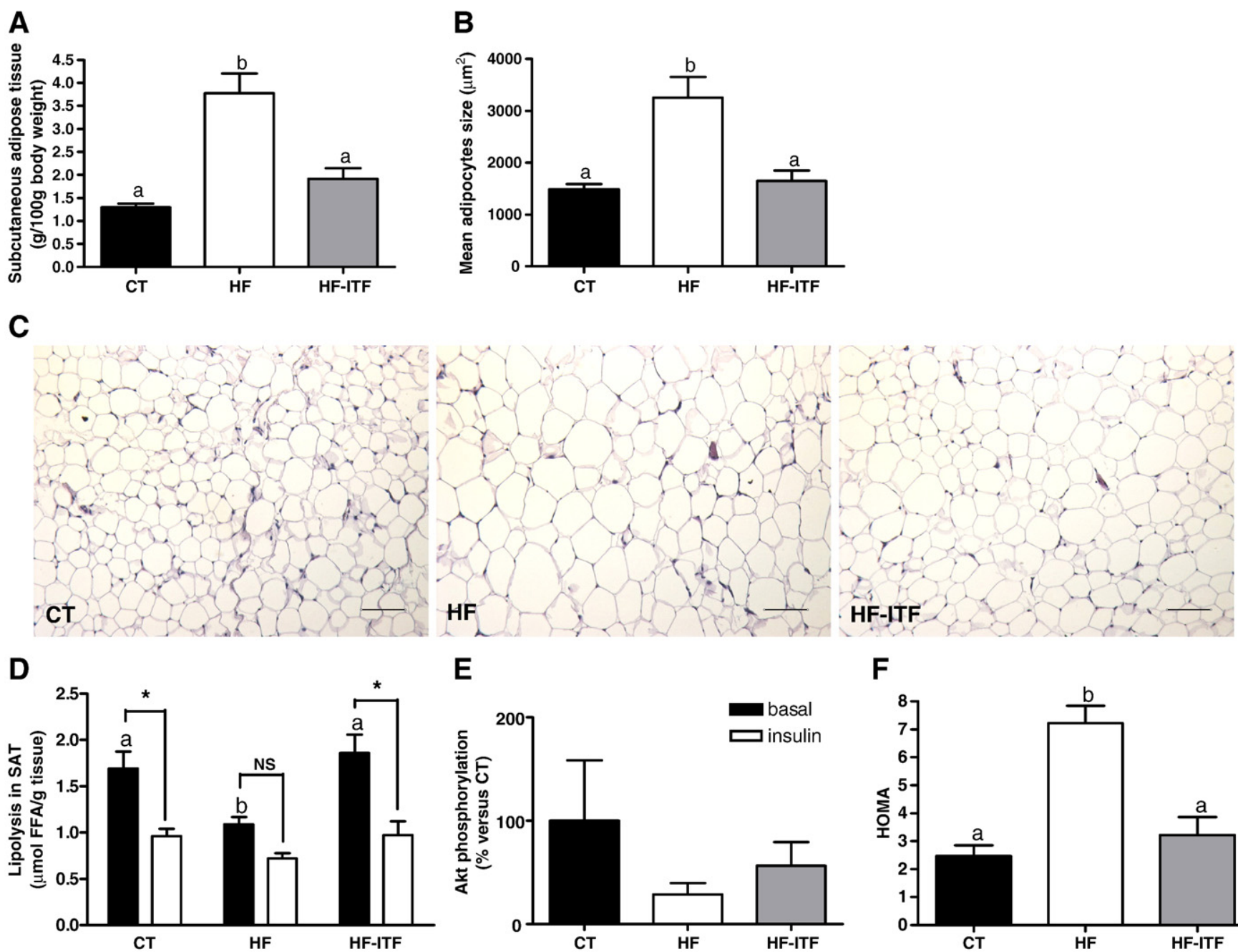

E

$\mathbf{F}$
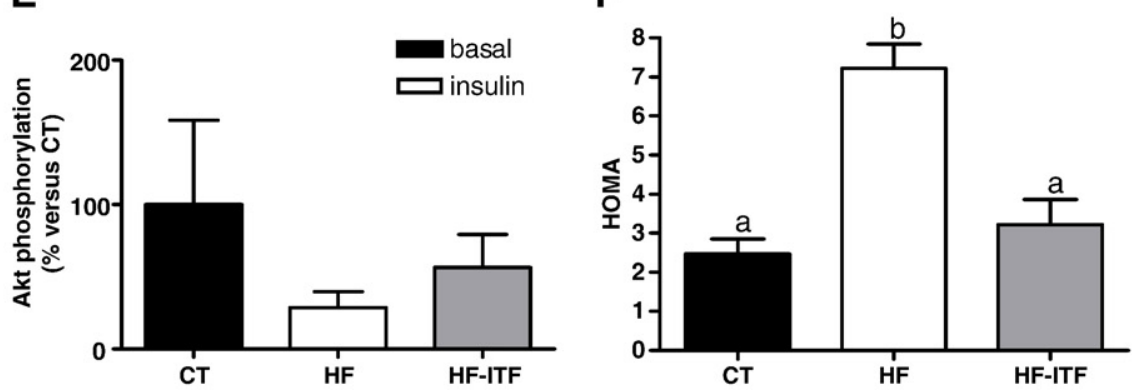

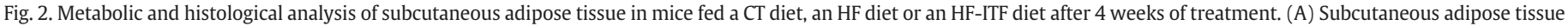

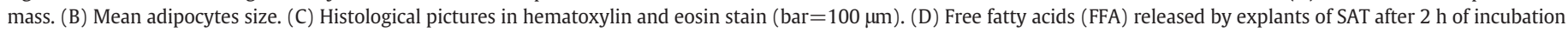

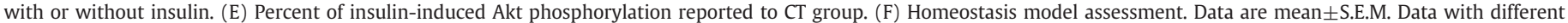

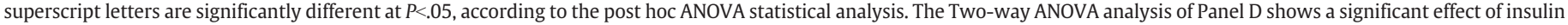
and treatment $(P<.05) ;{ }^{*} P<.05$ "basal lipolysis" versus "insulin-inhibited lipolysis" according to Bonferroni posttest.

of the analyzed bacterial groups, except for bifidobacteria. As expected, the co-administration of the HF diet with ITF significantly increased bifidobacterial counts by 100 -fold. However, ITF treatment also led to a drop in Roseburia spp. and of Clostridium cluster XIVa.

Changes in the bacterial composition were also assessed with DGGE fingerprinting analysis of different bacterial groups. The combination of all different fingerprints, followed by similarity analysis using PCoA, indeed confirmed that the composition of the microbial community was strongly affected by the type of diet which was administered to the animals (Fig. 1B). A representative DGGE gel for general bacteria is shown in supplemental data (SD 1).

\subsection{ITF prebiotics lessen fat mass development driven by the HF diet}

Energy intake was monitored twice a week during the treatment. Total energy consumption, calculated upon diet's energy content and prebiotic supplementation in water, tended to increase in HF-fed mice and was not modified by ITF treatment (CT: 11.15, HF: 15.07 , HFITF: $13.79 \mathrm{kcal} /$ day per mouse). Fat ingestion was strongly increased in $\mathrm{HF}$ fed mice versus $\mathrm{CT}$, and prebiotics did not modify this parameter in a significant way (CT: 0.101; HF: 1.725 ; HF-ITF: $1.579 \mathrm{~g}$ fat/day per mouse). Moreover, ITF prebiotics blunted the HF diet-induced body weight gain (CT: $2.29 \pm 0.21$; HF: $8.08 \pm 0.86$; HF-ITF: $4.57 \pm 0.55$ g) and subcutaneous adipose tissue accumulation (Fig. 2A), despite the similar fat ingestion.

\subsection{ITF prebiotics increase basal lipolysis and improve adipose tissue insulin response}

Mean adipocyte size in SAT was significantly increased in HF-fed mice versus CT, whereas ITF treatment normalized this parameter (Fig. 2B and 2C). In this tissue, basal lipolysis - estimated through the release of free fatty acids in the medium - was decreased by the HF diet and restored by the supplementation with ITF (Fig. 2D). Similar results were obtained when glycerol was measured in the culture medium as an index of lipolysis (data not shown). Moreover, lipolysis inhibition by insulin was lower in explants of SAT from HF-fed mice in comparison to explants from CT mice and ITF restored insulin effect to the level of CT group (Fig. 2D). The insulin-induced Akt phosphorylation, which reflects the response to insulin, tended to decrease in explants of SAT of HF-fed mice versus CT animals and was partially restored in ITF-treated mice (Fig. 2E). In accordance with this result, the HF diet-induced an important increase of insulin resistance index (HOMA) value and this was counteracted by the addition of ITF (Fig. 2F). 
A

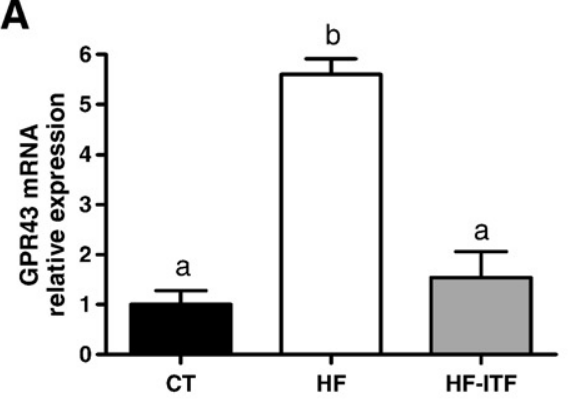

C

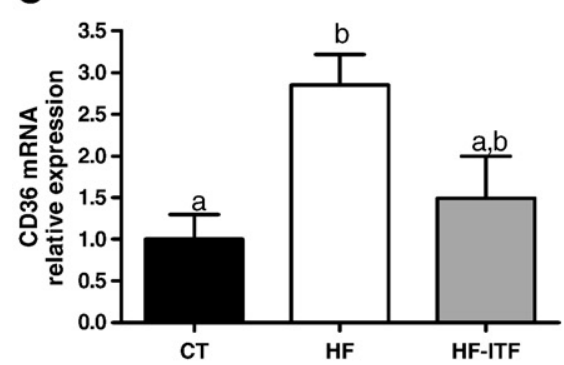

D

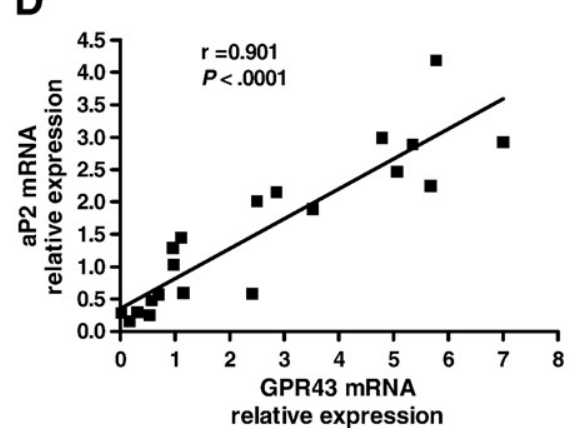

B
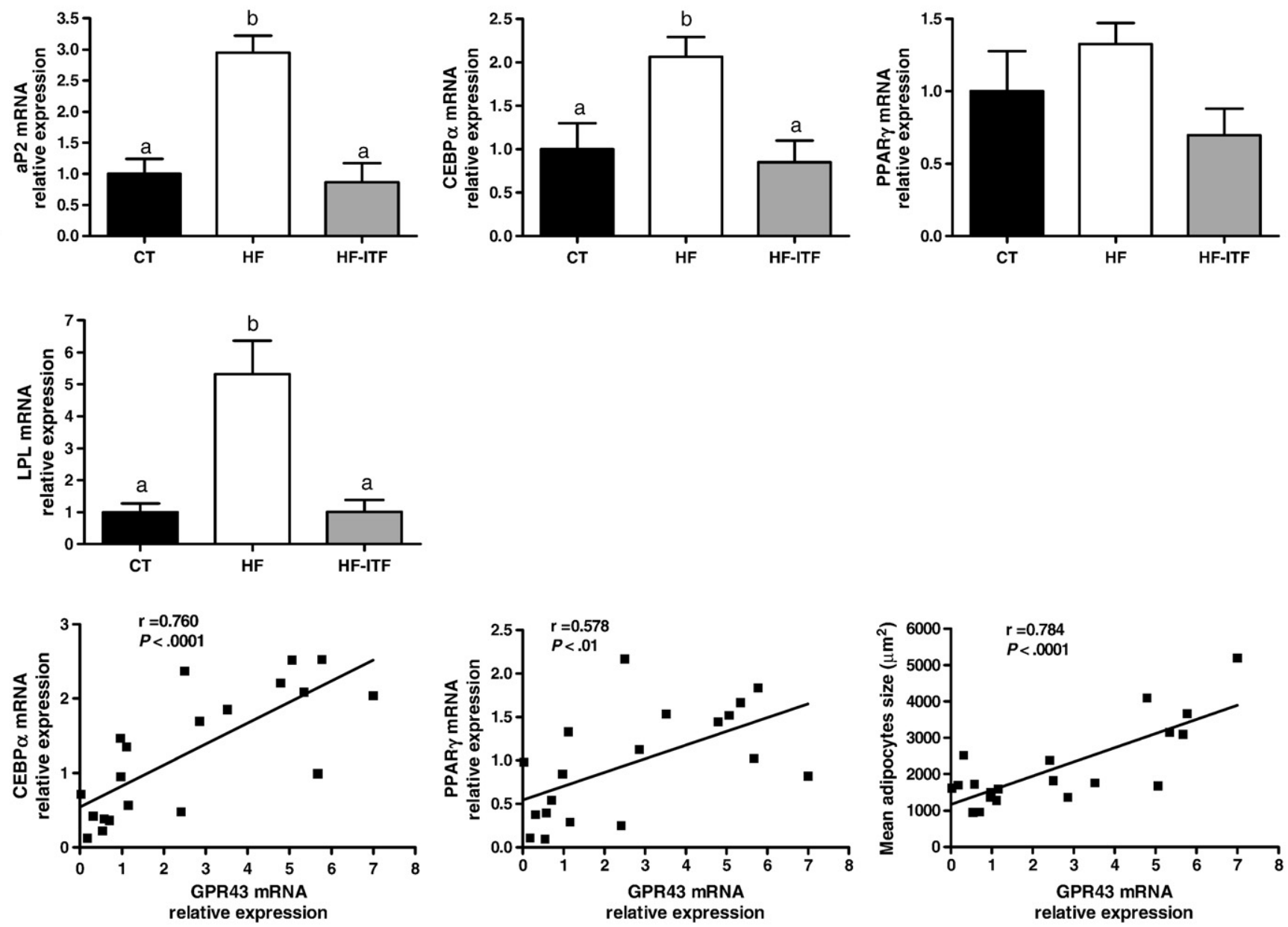

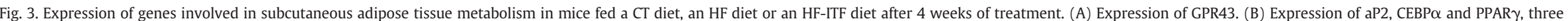

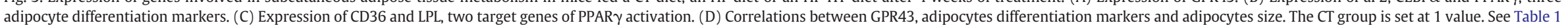
for primer sequences and abbreviations. Data are mean \pm S.E.M. Data with different superscript letters are significantly different at $P<.05$, according to the post hoc ANOVA statistical analysis. 
3.4. ITF prebiotics blunt the increase in GPR43 and differentiationrelated gene expression occurring in the subcutaneous adipose tissue of HF-fed mice

Since GPR43 is implicated in both lipolysis regulation and adipocyte differentiation [14,15], the expression of this receptor was measured and its variation was correlated with key factors controlling adipocyte differentiation. The HF diet increased GPR43 mRNA fivefold and this effect was blunted by ITF (Fig. 3A). The HF treatment also significantly increased aP2 mRNA content in the subcutaneous adipose tissue, while the HF-ITF group showed an expression similar to the CT group. The same profile was observed for $\mathrm{C} / \mathrm{EBP} \alpha \mathrm{mRNA}$. Surprisingly, PPAR $\gamma$ expression was not modified by HF diet but ITF tended to decrease its expression in comparison to HF group (Fig. 3B). Target genes of PPAR $\gamma$, namely CD36 and LPL mRNA, were increased in HF fed mice and the addition of ITF counteracted this effect (Fig. 3C). Finally, GPR43 expression was positively and significantly correlated to aP2, C/EBP $\alpha$ and PPAR $\gamma$ mRNAs but also to adipocytes size (Fig. 3D).

3.5. ITF prebiotics do not influence the changes in fatty acid profile occurring in subcutaneous adipose tissue of HF-fed mice

Dietary lipids have an impact on the fatty acid profile in adipose tissue $[28,29]$. Moreover, it has been clearly demonstrated that a number of fatty acids, especially polyunsaturated fatty acids (PUFAs), can bind and activate PPAR $\gamma$ at micromolar concentrations [30,31]. Therefore, the fatty acid pattern was analyzed in SAT of mice fed the HF diet plus or minus prebiotics. Fig. 4 shows the SAT levels of fatty acids present in the HF diet and/or able to activate PPAR $\gamma$. Some of them
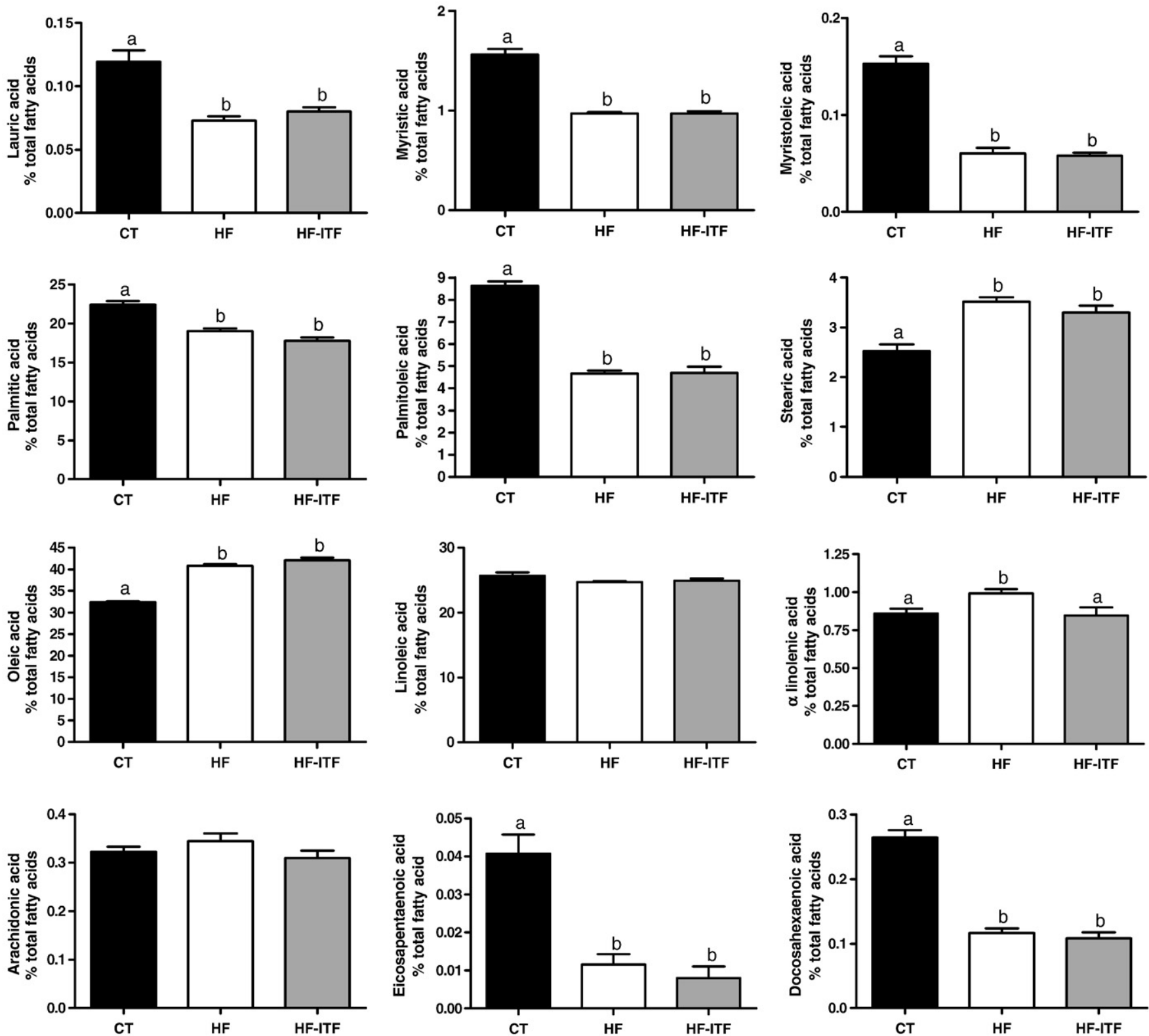

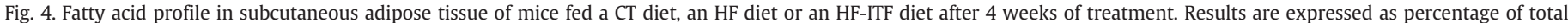
identified fatty acid. Data are mean \pm S.E.M. Data with different superscript letters are significantly different at $P<.05$, according to the post hoc ANOVA statistical analysis. 

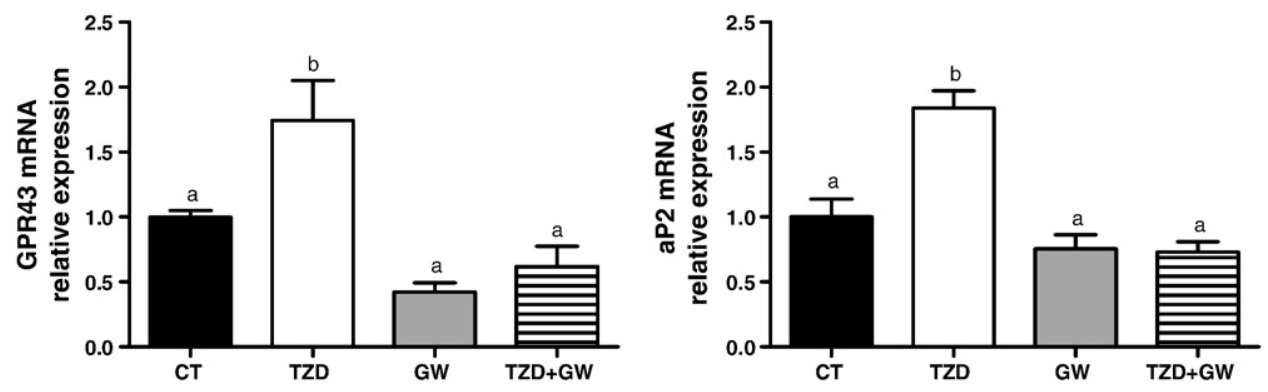

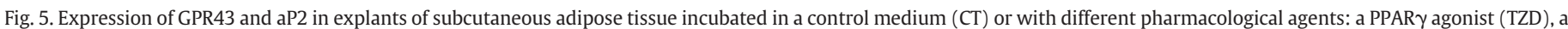

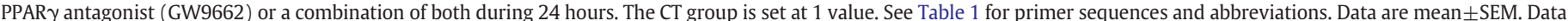
with different superscript letters are significantly different at $P<.05$, according to the post hoc ANOVA statistical analysis.

were significantly decreased whereas others, among which oleic acid and $\alpha$-linolenic acid, two potent PPAR $\gamma$ activators, were increased by the HF diet. The coadministration of ITF did not modify the HF dietinduced fatty acid pattern. The slight but significant decrease of $\alpha$ linolenic acid observed upon prebiotic feeding was not significant anymore when results were expressed in $\mu \mathrm{g} / \mathrm{mg}$ tissue (data not shown). It is important to note that the fatty acids profile in SAT did not fit with the composition of the diets except for stearic, oleic and $\alpha$ linolenic acids that were both increased in HF diet and in adipose tissue of HF fed mice (Supplemental data 2).
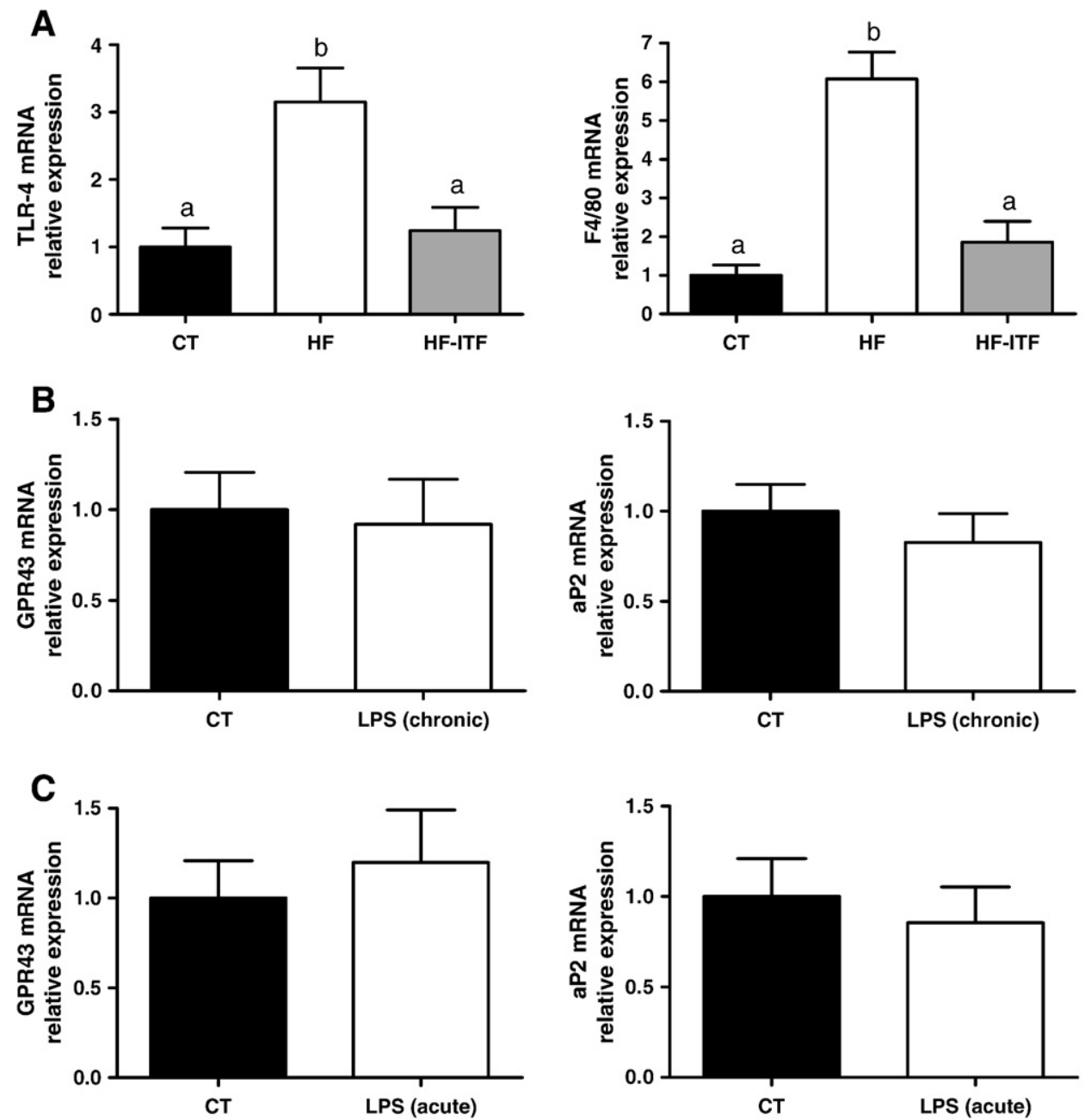

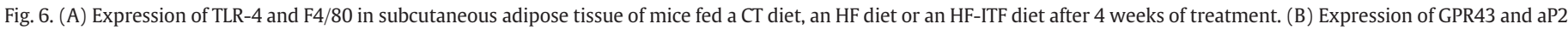

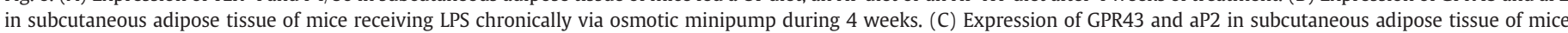

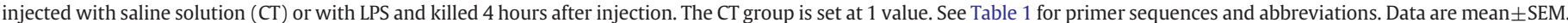
Data with different superscript letters are significantly different at $P<.05$, according to the post hoc ANOVA statistical analysis. 
3.6. Implication of PPAR $\gamma$ activation in the modification of GPR43 occurring in SAT upon HF and prebiotics treatment

As shown in our HF study, a modulation of PPAR $\gamma$ activity could have an impact on GPR43 expression. Based on an ex vivo experiment, we found that a PPAR $\gamma$ agonist (thiazolidinedione; TZD) significantly increased GPR43 mRNA level as compared to the CT conditions. This effect was abolished when SAT explants were incubated in the presence of a PPAR $\gamma$ antagonist (GW9662). Similar results were observed for aP2 mRNA (Fig. 5).

\subsection{LPS is not directly involved in the modulation of GPR43 expression} in $S A T$

HF diets have been shown to promote obesity and insulin resistance, namely by favoring LPS translocation from the gut, a phenomenon negatively controlled by prebiotics $[7,8]$. In the present experiment, we confirmed that the HF diet increased the expression of TLR4 and F4/80 in SAT and that this was counteracted by the supplementation with ITF (Fig. 6A). In order to study the potential impact of LPS on GPR43 and related-adipocyte differentiation gene expression, we used two models of LPS-induced inflammation. In mice chronically infused during 1 month with low doses of LPS mimicking endotoxemia which occurs upon HF feeding - no modification in GPR43 and aP2 expression in SAT was observed as compared to the CT group (Fig. 6B). In mice receiving an acute load of LPS (ip) and killed $4 \mathrm{~h}$ after the single injection, again, no modification of GPR43 and aP2 mRNA in SAT was detected (Fig. 6C).

\section{Discussion}

Obesity is characterized by an excess of fat mass and has been associated to an altered gut microbiota composition [1,2]. In this context, prebiotics such as ITF are considered as a nutritional tool to promote bacterial fermentation, to induce qualitative changes of gut microbiota and, thereby, to counteract fat mass development and related metabolic disorders $[8,10,17]$. In our study, we showed that an HF diet - which also contains digestible carbohydrates - led to changes in gut microbial composition that differ from the ones observed when mice were fed a HF/low-carbohydrate diet [8]. The HF diet used in our study led to a drop in total bacterial counts and in the counts of most of the analyzed bacterial groups, except for bifidobacteria. As expected, an important increase in bifidobacteria level occurred upon the coadministration of the HF diet and ITF. This confirms the classical prebiotic effect of ITF in this model of dietinduced obesity. However, ITF in this model also led to a decrease of both Roseburia spp and the counts of Clostridium cluster XIVa, a fact that is more surprising, since Roseburia is involved in "metabolic" cooperation with bifidobacteria for the use of fructans as metabolic substrates [32]. As previously described, ITF prebiotics counteracted the HF diet-induced body weight gain and fat mass accumulation in our conditions. We also confirmed that, in HF and HF-ITF groups, a negative correlation was observed between fat mass and bifidobacteria. Moreover, we found here a positive correlation between fat mass and Clostridium clusters XIVa, whereas no correlation was found for Roseburia spp. (Supplemental data 3).

We focused our metabolic studies on the SAT because it is a homogenous tissue which is metabolically active, and because its weight is decreased by prebiotics in most studies reporting this parameter $[8,10,27,33,34]$. Histological pictures of SAT explants show that the adipocytes were larger upon the HF treatment and got smaller when the HF diet was combined with ITF. This was further confirmed by the determination of the adipocytes surface which was significantly increased by HF diet, yet counteracted by ITF. This modulation of adipocytes size could be partly linked to changes in basal lipolysis, which is decreased in explants of SAT coming from HF-fed animals and restored to the CT level in ITF treated animals. Large adipocytes are additionally characterized by altered insulin sensitivity $[35,36]$. Our results are in accordance with this since the insulin-induced phosphorylation of Akt tended to decrease in explants of SAT upon HF diet and was partially restored in the presence of ITF. The inhibition of lipolysis by insulin was indeed diminished upon HF feeding whereas the ITF restored the response to insulin in the SAT explants. This is in agreement with the impaired insulin sensitivity in HF-fed animals and the restoration by ITF. Finally, the insulin sensitivity index, HOMA, confirmed that ITF-prebiotics could counteract the HF diet-induced insulin resistance. Therefore, if an increased basal lipolysis can be evoked to explain a lower fat mass development upon the prebiotic treatment, the higher adipose tissue insulin sensitivity could counteract this effect in the postprandial state.

It has been demonstrated that the activation of GPR43 in the adipose tissue by SCFA drives the inhibition of lipolysis [15] and stimulate adipocyte differentiation [14]. In order to test the potential implication of GPR43 in the modulation of adipose tissue metabolism by prebiotics in HF-fed animals, we measured GPR43 expression in the SAT. The HF diet indeed led to a strong increase in GPR43 mRNA levels, thereby confirming the data published by Hong et al. [14]. Interestingly, the ITF-prebiotics completely blunted the effect of the HF diet on GPR43 expression. This could not be explained by changes in total fat intake, which was not modified by prebiotic treatment.

To test the effect of prebiotics on adipocyte differentiation, genes involved in this process have been analyzed in our model. aP2 and C/ EBP $\alpha$ mRNAs were increased by the HF diet and restored to basal level by ITF. This was correlated with the observed changes in GPR43 expression. Unexpectedly, PPAR $\gamma$ expression was not modified in the same way as these two markers of adipogenesis even though this receptor is known to be a master regulator of this process [37]. Therefore, we postulated that the increased adipocyte differentiation in HF-fed mice was not related to a modification of PPAR $\gamma$ expression but rather to a modulation of its activation. To test this hypothesis, we measured expression of genes well known to be up-regulated by PPAR $\gamma$ agonists, as markers for PPAR $\gamma$ activation, namely CD36 and LPL $[38,39]$. As expected, CD36 and LPL mRNAs were significantly increased by the HF diet and ITF down-regulated their expression. Moreover, as these two genes are implicated in lipid accumulation in adipocytes, the changes in the expression of GPR43 and PPAR $\gamma$ activated genes are in accordance with the decrease in fat mass development by ITF-prebiotics in HF-fed animals. In addition, even if PPAR $\gamma$ expression was not significantly modified by dietary treatments, we highlighted a positive correlation between this parameter and GPR43 expression and this supports the hypothesis of a link between PPAR $y$ and GPR43.

Several fatty acids, especially PUFAs, can bind and activate PPAR $\gamma$ at micromolar concentrations $[30,31]$. To determine whether some fatty acids present in the SAT and coming from the HF diet could induce the PPAR $\gamma$ activation and so the over-expression of PPAR $\gamma$ target genes, the fatty acid pattern was analysed in SAT. Two well known PPAR $\gamma$ activators, namely oleic acid and $\alpha$-linolenic acid, were significantly increased in SAT of HF fed mice thus supporting our hypothesis. However, the coadministration of ITF did not modify this fatty acid pattern and so did not allow explaining the inhibition of HF diet-induced PPAR $\gamma$ activation and over-expression of PPAR $\gamma$ target genes upon ITF. Nevertheless, we may not be sure that those fatty acids are present in a sufficient concentration within the nuclei to activate PPAR $\gamma$ and that could maybe explain the lack of effect of ITF treatment.

At that stage, we did not know yet whether the increase in GPR43 expression upon the HF diet and the counteracting effect of ITFprebiotics preceded or followed modulation of PPAR $\gamma$ activity. To 
address this question, we incubated subcutaneous adipose tissue explants ex vivo with a PPARy agonist (TZD) and/or a PPARy antagonist (GW9662). The PPAR $\gamma$ agonist increased GPR43 expression in this adipose tissue model, as previously suggested in adipocyte cell model (3T3-L1) [14]. Moreover, the PPAR $\gamma$ antagonist blunted the expression of GPR43 in adipose tissue explants suggesting that compounds that exert an antagonist effect on PPAR $\gamma$ could be implicated in the modulation of GPR43 expression upon the prebiotic treatment. The same profile was observed for aP2 expression. In view of these results and the positive correlations highlighted between GPR43 and differentiation-related genes, we can propose a link between this $G$ protein-coupled receptor and PPAR $\gamma$ activation. Moreover, we found in literature that the modulation of PPAR $\gamma$ activity by PPAR $\gamma$ agonists or antagonists had an impact on adipocytes size [40-42]. Therefore, the link between the three events (PPAR $\gamma$ activation, adipocytes size and GPR43) seems relevant.

One question however remained: could LPS be involved in GPR43 expression changes upon HF and ITF treatments? We have previously shown that an HF diet increases the serum levels of LPS, that this increase is involved in fat mass development, and that this effect may be counteracted by ITF-prebiotics [7,8]. Indeed, the fact that both TLR4 and F4/80 expression were increased in the SAT of HF-fed mice and that this effect was counteracted by ITF administration is a confirmation of the likely involvement of LPS in adipose tissue metabolism. To investigate whether LPS could be a driver of GPR43 modulation in the adipose tissue, two experimental protocols were designed to study the impact of LPS on GPR43 and adipocyte differentiation genes expression. In a first experiment, mice were submitted to a chronic load of LPS administered via an osmotic minipump during 4 weeks. The chronic treatment with LPS, however, did not modify GPR43 mRNA or the expression of the adipocyte differentiation marker, aP2, in SAT. Next, mice were submitted to an acute load of LPS and killed 4 hours after the intra-peritoneal injection. Similarly to the chronic LPS treatment, LPS had no impact on the expression of GPR43 and aP2. We also measured the expression of other PPAR $\gamma$-activated genes (CD36 and LPL) and they were not modified by an acute load of LPS (data not shown). All these results counteract the hypothesis of a key role of LPS in the modulation of GPR43 expression occurring upon the HF treatment.

In conclusion, the HF diet used in our study induced important changes in adipose tissue metabolism including an increase in adipogenesis (overexpression of differentiation-related genes like aP2 and C/EBP $\alpha$ but also over-expression of genes implicated in lipid storage such as CD36 and LPL), a decrease in basal lipolysis and a lower response to insulin in explants of SAT. These effects seemed related to an activation of PPAR $\gamma$, as shown by the overexpression of PPAR $\gamma$ target genes. Moreover, PPAR $\gamma$ activation could be a driver of the important increase of GPR43 expression upon HF feeding whereas LPS did not seem to be implicated in this effect. Interestingly, the administration of ITF-prebiotics to HF-fed mice led to an important increase of bifidobacteria levels and counteracted all the HF dietinduced alterations, including a restoration to the CT level of PPAR $\gamma$ activity and GPR43 expression. The specific modulation of the gut microbiota by prebiotics is an interesting tool to modulate adipose tissue metabolism which is altered in obesity. However, we do not know yet how ITF-prebiotics counteract HF diet-induced PPAR $\gamma$ activation. A specific study could be devoted to the mechanism by which ITF blunt PPAR $\gamma$ activation, in order to propose this nutritional approach in the management of fat mass development and obesity.

The following are the supplementary materials related to this article Supplemental data 1. General bacteria DGGE gel (Pearson Correlation) performed on the cecum content of mice ( $n=8 /$ group) fed a CT diet (Symbols 1-8), an HF diet (HF, Symbols 9-16) or an HFITF diet (Symbols 17-24) during 4 weeks.Supplemental data 2. Fatty acid composition of the two diets: the $\mathrm{AO} 4$ diet or $\mathrm{CT}$ diet and the $\mathrm{HF}$ diet. Results are expressed in $\mathrm{g}$ FA/kg diet. Supplemental data 3. Correlations between fat mass and bifidobacteria (A), Clostridium cluster XIVa (B) and Roseburia spp. (C) in mice fed a CT diet, an HF diet or an HF-ITF diet after 4 weeks of treatment.

Supplementary data associated with this article can be found, in the online version, at doi:10.1016/j.jnutbio.2010.05.009.

\section{Acknowledgments}

Patrice D. Cani is a Research Associate, Louise Deldicque a Postdoctoral Researcher and Laure B. Bindels a Research Fellow from the FNRS Belgium. We thank Damien Naslain, Fabienne De Backer and Christine Turu for their technical assistance. This project was supported by a FNRS grant (no. 1.5.095.09F).

\section{References}

[1] Ley RE, Backhed F, Turnbaugh P, Lozupone CA, Knight RD, Gordon JI. Obesity alters gut microbial ecology. Proc Natl Acad Sci U S A 2005;102:11070-5.

[2] Ley RE. Obesity and the human microbiome. Curr Opin Gastroenterol 2010;26: 5-11.

[3] Cani PD, Delzenne NM. The role of the gut microbiota in energy metabolism and metabolic disease. Curr Pharm Des 2009;15:1546-58.

[4] Cani PD, Delzenne NM. Interplay between obesity and associated metabolic disorders: new insights into the gut microbiota. Curr Opin Pharmacol 2009;9: 737-43.

[5] Backhed F, Ding H, Wang T, Hooper LV, Koh GY, Nagy A, et al. The gut microbiota as an environmental factor that regulates fat storage. Proc Natl Acad Sci U S A 2004;101:15718-23.

[6] Backhed F, Manchester JK, Semenkovich CF, Gordon JI. Mechanisms underlying the resistance to diet-induced obesity in germ-free mice. Proc Natl Acad Sci U S A 2007;104:979-84.

[7] Cani PD, Amar J, Iglesias MA, Poggi M, Knauf C, Bastelica D, et al. Metabolic endotoxemia initiates obesity and insulin resistance. Diabetes 2007;56:1761-72.

[8] Cani PD, Neyrinck AM, Fava F, Knauf C, Burcelin RG, Tuohy KM, et al. Selective increases of bifidobacteria in gut microflora improve high-fat-diet-induced diabetes in mice through a mechanism associated with endotoxaemia. Diabetologia 2007;50:2374-83.

[9] Cani PD, Bibiloni R, Knauf C, Waget A, Neyrinck AM, Delzenne NM, et al. Changes in gut microbiota control metabolic endotoxemia-induced inflammation in high-fat diet-induced obesity and diabetes in mice. Diabetes 2008;57:1470-81.

[10] Cani PD, Possemiers S, Van de Wiele T, Guiot Y, Everard A, Rottier O, et al. Changes in gut microbiota control inflammation in obese mice through a mechanism involving GLP-2-driven improvement of gut permeability. Gut 2009;58: 1091-103.

[11] Swaminath G. Fatty acid binding receptors and their physiological role in type 2 diabetes. Arch Pharm (Weinheim) 2008;341:753-61.

[12] Samuel BS, Shaito A, Motoike T, Rey FE, Backhed F, Manchester JK, et al. Effects of the gut microbiota on host adiposity are modulated by the short-chain fatty-acid binding G protein-coupled receptor, Gpr41. Proc Natl Acad Sci U S A 2008;105: 16767-72.

[13] Ichimura A, Hirasawa A, Hara T, Tsujimoto G. Free fatty acid receptors act as nutrient sensors to regulate energy homeostasis. Prostaglandins Other Lipid Mediat 2009;89:82-8.

[14] Hong YH, Nishimura Y, Hishikawa D, Tsuzuki H, Miyahara H, Gotoh C, et al. Acetate and propionate short chain fatty acids stimulate adipogenesis via GPCR43. Endocrinology 2005;146:5092-9.

[15] Ge H, Li X, Weiszmann J, Wang P, Baribault H, Chen JL, et al. Activation of G protein-coupled receptor 43 in adipocytes leads to inhibition of lipolysis and suppression of plasma free fatty acids. Endocrinology 2008;149:4519-26.

[16] Roberfroid M. Prebiotics: the concept revisited. J Nutr 2007;137:830S-7S.

[17] Delmee E, Cani PD, Gual G, Knauf C, Burcelin R, Maton N, et al. Relation between colonic proglucagon expression and metabolic response to oligofructose in high fat diet-fed mice. Life Sci 2006;79:1007-13.

[18] Gerhold DL, Liu F, Jiang G, Li Z, Xu J, Lu M, et al. Gene expression profile of adipocyte differentiation and its regulation by peroxisome proliferator-activated receptor-gamma agonists. Endocrinology 2002;143:2106-18.

[19] de Wiele TV, Boon N, Possemiers S, Jacobs H, Verstraete W. Prebiotic effects of chicory inulin in the simulator of the human intestinal microbial ecosystem. FEMS Microbiol Ecol 2004:51:143-53.

[20] Possemiers S, Verthe K, Uyttendaele S, Verstraete W. PCR-DGGE-based quantification of stability of the microbial community in a simulator of the human intestinal microbial ecosystem. FEMS Microbiol Ecol 2004;49:495-507.

[21] Possemiers S, Bolca S, Grootaert C, Heyerick A, Decroos K, Dhooge W, et al. The prenylflavonoid isoxanthohumol from hops (Humulus lupulus L.) is activated into the potent phytoestrogen 8-prenylnaringenin in vitro and in the human intestine. J Nutr 2006;136:1862-7. 
[22] Ramirez-Farias C, Slezak K, Fuller Z, Duncan A, Holtrop G, Louis P. Effect of inulin on the human gut microbiota: stimulation of Bifidobacterium adolescentis and Faecalibacterium prausnitzii. Br J Nutr 2009;101:541-50.

[23] Guo X, Xia X, Tang R, Zhou J, Zhao H, Wang K. Development of a real-time PCR method for Firmicutes and Bacteroidetes in faeces and its application to quantify intestinal population of obese and lean pigs. Lett Appl Microbiol 2008;47:367-73.

[24] Rinttila T, Kassinen A, Malinen E, Krogius L, Palva A. Development of an extensive set of $16 \mathrm{~S}$ rDNA-targeted primers for quantification of pathogenic and indigenous bacteria in faecal samples by real-time PCR. J Appl Microbiol 2004:97:1166-77.

[25] Rochon L, Bukowiecki LJ. Alterations in adipocyte response to lipolytic hormones during cold acclimation. Am J Physiol 1990;258:C835-40.

[26] Festuccia WT, Laplante M, Berthiaume M, Gelinas Y, Deshaies Y. PPARgamma agonism increases rat adipose tissue lipolysis, expression of glyceride lipases, and the response of lipolysis to hormonal control. Diabetologia 2006;49:2427-36.

[27] Cani PD, Knauf C, Iglesias MA, Drucker DJ, Delzenne NM, Burcelin R. Improvement of glucose tolerance and hepatic insulin sensitivity by oligofructose requires a functional glucagon-like peptide 1 receptor. Diabetes 2006;55:1484-90.

[28] Awad AB. Effect of dietary lipids on composition and glucose utilization by rat adipose tissue. J Nutr 1981:111:34-9.

[29] Suzuki S, Ishikawa S, Arihara K, Itoh M. Molecular species-specific differences in composition of triacylglycerols of mouse adipose tissue and diet. Nutr Res 2008;28:258-62.

[30] Kliewer SA, Sundseth SS, Jones SA, Brown PJ, Wisely GB, Koble CS, et al. Fatty acids and eicosanoids regulate gene expression through direct interactions with peroxisome proliferator-activated receptors alpha and gamma. Proc Natl Acad Sci U S A 1997;94:4318-23.

[31] Xu HE, Lambert MH, Montana VG, Parks DJ, Blanchard SG, Brown PJ, et al. Molecular recognition of fatty acids by peroxisome proliferator-activated receptors. Mol Cell 1999;3:397-403.
[32] Falony G, Vlachou A, Verbrugghe K, De VL. Cross-feeding between Bifidobacterium longum BB536 and acetate-converting, butyrate-producing colon bacteria during growth on oligofructose. Appl Environ Microbiol 2006;72:7835-41.

[33] Cani PD, Neyrinck AM, Maton N, Delzenne NM. Oligofructose promotes satiety in rats fed a high-fat diet: involvement of glucagon-like Peptide-1. Obes Res 2005;13:1000-7.

[34] Cani PD, Hoste S, Guiot Y, Delzenne NM. Dietary non-digestible carbohydrates promote L-cell differentiation in the proximal colon of rats. Br J Nutr 2007;98: 32-7.

[35] Okuno A, Tamemoto H, Tobe K, Ueki K, Mori Y, Iwamoto K, et al. Troglitazone increases the number of small adipocytes without the change of white adipose tissue mass in obese Zucker rats. J Clin Invest 1998;101:1354-61.

[36] Hajer GR, van Haeften TW, Visseren FL. Adipose tissue dysfunction in obesity, diabetes, and vascular diseases. Eur Heart J 2008;29:2959-71.

[37] Rosen ED, Sarraf P, Troy AE, Bradwin G, Moore K, Milstone DS, et al. PPAR gamma is required for the differentiation of adipose tissue in vivo and in vitro. Mol Cell 1999;4:611-7.

[38] Berger J, Moller DE. The mechanisms of action of PPARs. Annu Rev Med 2002;53: 409-35.

[39] Stienstra R, Duval C, Muller M, Kersten S. PPARs, obesity, and inflammation. PPAR Res 2007;2007:95974

[40] Berger JP, Akiyama TE, Meinke PT. PPARs: therapeutic targets for metabolic disease. Trends Pharmacol Sci 2005;26:244-51.

[41] de Souza CJ, Eckhardt M, Gagen K, Dong M, Chen W, Laurent D, et al. Effects of pioglitazone on adipose tissue remodeling within the setting of obesity and insulin resistance. Diabetes 2001:50:1863-71.

[42] Rieusset J, Touri F, Michalik L, Escher P, Desvergne B, Niesor E, et al. A new selective peroxisome proliferator-activated receptor gamma antagonist with antiobesity and antidiabetic activity. Mol Endocrinol 2002;16:2628-44. 